\title{
BRIEF
}

\section{The Lunch Bunch - A Meaningful and Impactful Conversation on Leadership}

\author{
Lea S. Eiland, PharmD, Sylvia E. Rogers, PhD
}

Auburn University, Harrison School of Pharmacy, Auburn, Alabama

Corresponding Author: Lea S. Eiland, Auburn University, Harrison School of Pharmacy, 2316 Walker Building, Auburn, AL 36849. Tel: 256-653-1743. Email: eilanls@auburn.edu

Submitted December 14, 2020; accepted July 6, 2021; ePublished July 2021

\begin{abstract}
Objective. To describe outcomes of an article club that was designed to foster leadership within our pharmacy school by informally gathering interested faculty and staff that provided a safe environment for discussion on leadership concepts. Methods. Participants discussed a Harvard Business Review's Top 10 Leadership article monthly. After ten sessions, participants were asked to complete an electronic survey on their perspectives of the activities and could volunteer for an interview. Descriptive statistics were calculated, and qualitative software assisted in analyzing interview transcripts. Videoconferencing allowed for off-campus faculty and staff participation. No direct programmatic costs were incurred. Results. Four to 24 participants attended each session. Sixteen participants completed the survey, with five volunteering for interviews. All 16 strongly agreed the sessions "increased awareness of leadership concepts," and 15 strongly agreed/agreed the activities "influenced my leadership decision-making" and "facilitated building a culture of leadership at the school." Interviews revealed mid-career faculty participated to learn about general leadership concepts from discussions, and some junior faculty participated to gain leadership skills to help with promotion. All participants noted they were exposed to novel leadership styles. Teaching and practice commitments were the two highest noted barriers to participating.
\end{abstract}

Conclusion. Providing an interactive discussion forum to learn and discuss leadership concepts and qualities is effective for personal growth and professional development. Other schools and institutions can implement similar activities to foster leadership.

Keywords: development, faculty, leadership, staff, workforce

\section{INTRODUCTION}

Many faculty and staff in higher education desire leadership training for career advancement; however, attending formal leadership programs may not be attainable due to personal or professional barriers. In an American College of Clinical Pharmacy white paper, Boyce and colleagues recommended developing leadership abilities as a faculty development program component for pharmacy practice faculty. ${ }^{1}$ Specifically, leadership definitions, theories, abilities, and styles were proposed for discussion. The authors stated leadership development would enhance faculty members' ability to complete their various responsibilities and be beneficial in promotion and tenure. Institutions may host periodic leadership development activities such as day-long seminars. However, participants may avoid activities that require longer time commitments due to time constraints and professional responsibilities.

Book and journal clubs are organizational activities that can facilitate the development of leadership skills. ${ }^{2-7}$ Example processes for conducting these activities have been described for pharmacy students, residents, and new practitioners. ${ }^{6,7}$ However, outcomes using this method for leadership development have not been published in the pharmacy literature.

A pharmacy practice faculty member (organizer) was inspired to develop a leadership article club. Leadership topics were not part of the school's faculty development activities, and the organizer saw a need to support leadership growth and development. Also, the school's new strategic plan had a priority to "establish a culture of community that empowers faculty and staff to become leaders, achieve professional excellence, and attain personal fulfillment." ${ }^{8}$ Through informal inquiry, other faculty members showed interest in a monthly article discussion rather than a book club format due to a perceived lack of time. The monthly leadership article club was designed to foster leadership within our pharmacy school by informally gathering interested faculty and staff to provide a safe environment for discussion on leadership concepts. This study evaluated participants' perspectives of the informal leadership development activity. Successes and challenges of designing and conducting this activity are presented. 


\section{METHODS}

This leadership development activity began in July 2018. Faculty and graduate students were invited to participate via an email invitation and calendar appointment. Starting in January, staff were also invited.

For the 2018-2019 series, the organizer assigned one article per month from Harvard Business Review's (HBR) 10 Must Reads on Leadership. ${ }^{9}$ Articles were available in Box (Box, Inc., Redwood City, CA), a cloud content management system, and accessed through a web link in the email and calendar appointment. The articles chosen were independent of each other, and only one article was discussed per session. This allowed flexibility in attendance as participants were not required to attend a prior session for understanding or application of a topic. The organizer prepared seven to eight reflective questions for each discussion session. The sessions were one hour (12-1 pm central time) and conducted via Zoom (Zoom Video Communications, Inc., San Jose, California), a video conferencing system, allowing attendees from the main, satellite, and six regional campuses to participate.

After ten sessions (July-November, January-May), participants who attended at least one session were invited to complete a twenty-item electronic anonymous questionnaire on their perspectives of the activity. For one survey item (Table 2), permission was obtained to use six verbatim and seven modified statements from a published nursing journal club activity. ${ }^{4}$ Participants could additionally volunteer for an interview to gather additional thoughts, attitudes, and perspectives. One of the authors met with each volunteer for 30 minutes to 1 hour and asked 13 open-ended questions about their views of the activities, personal leadership goals, and barriers to reaching those goals. The interviews were conducted through Zoom and recorded. Descriptive statistics were calculated from the quantitative data. Authors used qualitative software (QDA Miner Lite, Provalis Research, Montreal, QC) to code interview transcripts.

To analyze the qualitative data from the interviews, the authors conducted content analysis. Initially, the authors read the transcripts automatically generated from the video conferencing and corrected any errors. Next, authors coded each line of the transcripts using inductive in Vivo coding in which short phrases from the interview were assigned codes that represented the data. ${ }^{10}$ In Vivo coding was used because the authors were interested in the participants' perceptions and were not looking for specific utterances. Codes were grouped into categories during and after initial coding. Lastly, authors combined the categories into overarching themes. This study was approved by the institutional research board.

\section{RESULTS}

Participants attended an average of five sessions, with four to 24 participants $(M=9.4, S D=6.2)$ present in each session. Each session had remote-campus participants, including the organizer. Questionnaires were sent to 32 participants who attended at least one session. The response rate was 50\%, with sixteen participants completing the questionnaire and five faculty members volunteering for interviews. Most participants were from the pharmacy practice department, female, and had been faculty members for an average of 11 years (Table 1 ).

Attendees were asked perspectives on several statements related to the activities (Table 2). Overall, the participants found the selected HBR articles relevant. Six articles received a "very relevant" rating by all respondents who attended the respective session, with the other articles receiving the same rating by most respondents. Respondents stated the HBR articles to be valuable as the first reading series of the activity. Participants commented that they liked best the informal, safe, relaxed setting, the discussion with others, hearing others' perspectives, the dialogue with others outside their department, and the practical articles.

Teaching and practice commitments were participation barriers most often noted by attendees $(n=11$ and $n=9$, respectively). Two faculty noted no barriers, and one each stated research commitments, service (committee) commitments, administrative responsibilities, maternity leave, or time was a barrier. Fourteen (93\%) participants stated they would participate in the activity again, while one (7\%) stated they would not.

Interviews revealed mid-career faculty participated to learn from discussions, and some junior faculty participated to gain leadership skills to help with promotion. One faculty member who accepted a director position during that year commented that they participated in the leadership article club "to help" them in their new role. The most valuable part of the activity was the discussion. Participants noted they were exposed to leadership styles they were previously unaware of, and the article "Discovering Your Authentic Leadership" was the most valuable.

\section{DISCUSSION}

Fuentes called for pharmacy programs to develop succession plans and develop strong leadership pipelines in our current time. ${ }^{11}$ This leadership article activity is one small step that could lead to a fruitful pathway in developing leaders. Pharmacy organizations provide formal leadership training programs for faculty interested in obtaining leadership positions. As leaders are needed for our profession's future, schools must do their part developing succession plans and training faculty and staff for leadership positions within their institutions and the academy. Implementing this activity 
could infuse leadership ideals throughout the organization. For instance, Rowlands and colleagues described an executive nursing leadership journal club that became incorporated into their culture and practice. ${ }^{3}$ Duffy and colleagues developed a leadership journal club for nurses to increase the awareness of evidence-based nursing leadership. ${ }^{4}$ Similar to our findings, nurses stated the activity increased their knowledge and perceived leader competency.

This unique leadership development activity presents a successful strategy to engage faculty and staff to discuss leadership concepts and promote advancement. In general, participants who attended sessions actively participated in the discussion, including the organizer. Participants' opinions of the article, interpretation and application of the leadership concepts, and personal experiences were shared. A comfortable and safe environment was created for discussion based on the engagement level of returning participants. As compared to Wombwell and colleagues' recommendations for conducting a leadership journal club, this activity was less structured, more informal, and focused on pharmacy school faculty and staff. Though the organizer prepared questions in advance, other discussion by participants was welcome. Participants could eat lunch during the session and were encouraged to attend even if they had not read the article beforehand. Additionally, the organizer focused on the HBR series, whereas Wombwell suggested various articles concentrated on six leadership areas. ${ }^{7}$

Twenty-four faculty members and administrators attended the first session, with one department head purchasing lunch for their six faculty members. This was the highest attended session, but not everyone actively participated in the discussion. In spring 2019, several faculty members were selected as directors in the school's new organizational structure. This may have increased participation as new directors may want to improve their leadership skills. Other participants may have thought learning about leadership would provide opportunities to gain leadership positions within the school through succession planning or professional organizations; thus, strengthening their service activities for promotion. Only one staff member attended; however, the sessions overlapped with some staff's lunch breaks. Having each session be independent of others allowed those to attend as their schedule allowed. Attendance likely would have significantly decreased if prior session attendance was required.

Leadership development can be formal or informal and can be extrapolated from other professions. The HBR articles fit well for stimulating discussion and growing professionally and personally. The concepts of leadership definitions, theories, abilities, and styles recommended by Boyce and colleagues to include in faculty development were covered in the ten articles and allowed for comparison of concepts. ${ }^{1}$ Participants stated the articles presented content that could be applied to their careers and would help them achieve personal or professional goals.

Gaufin and colleagues recommended facilitating leadership book clubs within the workplace as a practical and affordable activity. ${ }^{2}$ Our leadership development activity only had a direct cost of time as the articles were available through the university library system, and the university's videoconference system was used. Participants rated the design, setting, and frequency of the sessions positively. This activity was implemented pre-pandemic and continues today. As employees shifted to working remotely during the pandemic and potentially could continue to do so, this activity can easily be performed in an in-person, remote, or mixed work environment.

This activity had social and cultural benefits. Social connectedness is important in a geographically divided school, and participants stated the activity allowed interaction with other colleagues within the school. Most participants strongly agreed that the activity added to their job satisfaction and was worth the time invested, increasing well-being. Similar to Rowlands and colleagues' outcomes, our participants felt the activity facilitated building a leadership culture at the school, which is part of its strategic plan.

As anticipated, teaching and practice commitments were the most noted attendance barriers. Most participants belonged to the pharmacy practice department, where faculty traditionally have heavy teaching and practice responsibilities. Medina and colleagues described a virtual online book club on various topics, including leadership, conducted within an academic pharmacy organization's special interest group. ${ }^{5}$ Similar to the book club, ${ }^{5}$ our activity also saw a higher interest initially, yet a smaller group participated throughout the rest of the sessions. This could be because the participants did not find the activity valuable or, as stated in the survey response, time was an issue. To increase engagement, participants were surveyed after the first session seeking the best day and time for future sessions. Most responded, leading the organizer to think the session was valuable, though not all responders attended future meetings. Challenges for this type of activity exist. This activity was implemented at one school by a faculty member with a passion for leadership, but not all schools may have someone to lead this type of activity. Also, faculty and staff leadership development may not be a program's focus. Attendees elected to participate in this activity; thus, having an underlying level of interest in leadership. Participants were primarily from the pharmacy practice department, the school's largest department. Response rates to our survey and interview were low. As the activity is completing its third year, long-term analysis and outcomes of personal leadership goals will be assessed. 


\section{CONCLUSION}

As leaders are needed for the future of our profession, schools must do their part training faculty and staff for leadership positions. Providing a safe and interactive discussion forum to learn and discuss leadership concepts and qualities is effective for personal growth and professional development. Other schools and institutions can implement similar activities to foster leadership within their program and the profession.

\section{REFERENCES}

1. Boyce EG, Burkiewicz JS, Haase MR, et al. ACCP white paper: Essential components of a faculty development program for pharmacy practice faculty. Pharmacotherapy. 2008;28(10):245e-268e. https://www.accp.com/docs/positions/whitePapers/FacDevWPFinal_nd.pdf. Accessed March 3, 2021.

2. Gaufin JR, Kennedy KI, Struthers ED. Practical and affordable ways to cultivate leadership in your organization. J Public Health Manag Pract. 2010;16(2):156-161.

3. Rowlands A, Winslow S. The executive nursing leadership journal club. AORN J. 2011;94(2):190-3.

4. Duffy JR, Thompson D, Hobbs T. Evidence-Based Nursing Leadership. JONA. 2011;41(10):422-427.

5. Medina MS, Garrison GD, Brazeau GA. Finding time for faculty development. Am J Pharm Educ. 2010;74(10):Article 179.

6. Chappell A, Dervay K. Leadership Book Club: An Innovative Strategy to Incorporate Leadership Development Into Pharmacy Residency Programs. Hosp Pharm. 2016;51(8):635-638.

7. Wombwell E, Murray C, Davis SJ, Palmer K, Nayar M, Konkol J. Leadership journal club. Am J Health Syst Pharm. 2011;1;68(21):2026-2027.

8. Auburn University Harrison School of Pharmacy. 2019-2023 Strategic Plan. http://www.auburn.edu/academic/pharmacy/about/pdf/strategic-plan.pdf of Pharmacy Strategic Plan. Accessed March 3, 2021.

9. Harvard Business Review. HBR's 10 Must Reads on Leadership. https://store.hbr.org/product/hbr-s-10-mustreads-on-leadership-with-featured-article-what-makes-an-effective-executive-by-peter-f-drucker/12546. Accessed March 3, 2021.

10. Miles MB, Huberman AM, Saldaña J. Qualitative data analysis: A methods sourcebook. $3^{\text {rd }}$ ed. Los Angeles, CA: Sage Publications, 2014.

11. Fuentes DG. Rethinking Our Approaches to Succession Planning and Developing A Leadership Pipeline. Am J Pharm Educ. 2020; 84(12):8335. 
Participated In At Least One Session, $n=32, n \quad$ Completed Questionnaire, $n=16, n$ (\%) (\%)

Role

Faculty member

$29(91)$

Administrator

5 (18)

$16(100)$

Director

4 (14)

1 (6)

Graduate Student

2 (6)

Staff

1 (3)

Department Affiliation $^{\mathrm{a}}$

Pharmacy Practice

$21(66)$

$14(93)$

Health Outcomes Research and

$1(7)$

Drug Development and Discovery

Degree

Bachelor of Science

Doctor of Pharmacy

Master of Science

4 (13)

22 (69)

$4(18)$

1 (3)

$15(68)$

Doctor of Philosophy

$10(3)$

$1(5)$

2 (9)

Gender

Female

21 (66)

$13(81)$

Male

$11(34)$

3 (19)

Location

Main Campus

Satellite Campus

$18(56)$

6 (19)

Regional Campus

$8(25)$

Years as a Faculty Member/Staff

$0-5$

6-10

$4(25)$

4 (25)

11-15

2 (12)

15-20

$6(38)$

${ }^{\mathrm{a} O n e ~ s t a f f}$ member was affiliated with administration and no specific department. 


\begin{tabular}{|c|c|c|c|c|c|}
\hline $\begin{array}{l}\text { Rate the Following Statements: } \\
\text { The leadership article club... }\end{array}$ & $\begin{array}{l}\text { Strongly } \\
\text { agree, } \mathbf{n} \\
(\%)\end{array}$ & $\begin{array}{l}\text { Somewhat } \\
\text { agree, n } \\
(\%)\end{array}$ & $\begin{array}{c}\text { Neither } \\
\text { agree nor } \\
\text { disagree, } \mathbf{n} \\
(\%)\end{array}$ & $\begin{array}{l}\text { Somewhat } \\
\text { disagree, } \mathbf{n} \\
(\%)\end{array}$ & $\begin{array}{l}\text { Strongly } \\
\text { disagree, } \mathbf{n} \\
(\%)\end{array}$ \\
\hline $\begin{array}{l}\text { Increased my awareness of leadership } \\
\text { concepts }\end{array}$ & $16(100)$ & $0(0)$ & $0(0)$ & $0(0)$ & $0(0)$ \\
\hline $\begin{array}{l}\text { Reviewed relevant readings of } \\
\text { leadership concepts }\end{array}$ & $15(94)$ & $1(6)$ & $0(0)$ & $0(0)$ & $0(0)$ \\
\hline $\begin{array}{l}\text { Presented content appropriate for my } \\
\text { level of education }\end{array}$ & $16(100)$ & $0(0)$ & $0(0)$ & $0(0)$ & $0(0)$ \\
\hline $\begin{array}{l}\text { Created a safe environment for } \\
\text { discussion of leadership concepts }\end{array}$ & $15(94)$ & $1(6)$ & $0(0)$ & $0(0)$ & $0(0)$ \\
\hline Promoted dialogue of participants & $15(94)$ & $1(6)$ & $0(0)$ & $0(0)$ & $0(0)$ \\
\hline Allowed me to ask questions effectively & $14(88)$ & $2(13)$ & $0(0)$ & $0(0)$ & $0(0)$ \\
\hline $\begin{array}{l}\text { Allowed me to express my opinions } \\
\text { freely } \\
\text { Allowed me to comment on the article } \\
\text { and/ or other's viewpoints }\end{array}$ & $16(100)$ & $2(13)$ & $0(0)$ & $0(0)$ & $0(0)$ \\
\hline $\begin{array}{l}\text { Discussion encouraged me to think } \\
\text { about different viewpoints } \\
\text { Influenced my leadership decision }\end{array}$ & $14(88)$ & $2(13)$ & $0(0)$ & $0(0)$ & $0(0)$ \\
\hline making & $9(56)$ & $6(38)$ & $1(6)$ & $0(0)$ & $0(0)$ \\
\hline $\begin{array}{l}\text { Presented content that I could apply to } \\
\text { my career }\end{array}$ & $12(81)$ & $3(19)$ & $0(0)$ & $0(0)$ & $0(0)$ \\
\hline $\begin{array}{l}\text { Will help me achieve a personal or } \\
\text { professional goal }\end{array}$ & $9(56)$ & $5(31)$ & $1(6)$ & $1(6)$ & $0(0)$ \\
\hline Maintained my interest & $12(75)$ & $3(19)$ & $1(6)$ & $0(0)$ & $0(0)$ \\
\hline $\begin{array}{l}\text { Prompted me to learn new and different } \\
\text { information }\end{array}$ & $14(88)$ & $1(6)$ & $1(6)$ & $0(0)$ & $0(0)$ \\
\hline Was worth the time I invested & $14(88)$ & $1(6)$ & $1(6)$ & $0(0)$ & $0(0)$ \\
\hline $\begin{array}{l}\text { Facilitated building a culture of } \\
\text { leadership at the school } \\
\text { Allowed me to interact with other } \\
\text { colleagues within the school }\end{array}$ & $15(94)$ & $6(38)$ & $0(0)$ & $0(0)$ & $0(0)$ \\
\hline Added to my job satisfaction & $8(50)$ & $6(38)$ & $2(13)$ & $0(0)$ & $0(0)$ \\
\hline Included effective teaching methods & $11(69)$ & $4(25)$ & $1(6)$ & $0(0)$ & $0(0)$ \\
\hline $\begin{array}{l}\text { Was conducted in a setting conducive to } \\
\text { my needs } \\
\text { Was effectively conducted via }\end{array}$ & $14(88)$ & $1(6)$ & $1(6)$ & $0(0)$ & $0(0)$ \\
\hline videoconference & $15(94)$ & $1(6)$ & $0(0)$ & $0(0)$ & $0(0)$ \\
\hline $\begin{array}{l}\text { Was facilitated by a competent faculty } \\
\text { member } \\
\text { Was conducted at an appropriate time }\end{array}$ & $16(100)$ & $0(0)$ & $0(0)$ & $0(0)$ & $0(0)$ \\
\hline interval (once monthly) & $13(81)$ & $3(19)$ & $0(0)$ & $0(0)$ & $0(0)$ \\
\hline
\end{tabular}

